\title{
Urethral Fistula
}

National Cancer Institute

\section{Source}

National Cancer Institute. Urethral Fistula. NCI Thesaurus. Code C78668.

An abnormal communication between the urethra and another org an or anatomic site. 